\title{
Electronic parameters of MIS Schottky diodes with DNA biopolymer interlayer
}

\author{
ÖMER GÜLl $\ddot{U}^{1 *}$, ABDULMECIT TÜRÜT ${ }^{2}$ \\ ${ }^{1}$ Department of Physics, Faculty of Sciences and Arts, Batman University, Batman, Turkey \\ ${ }^{2}$ Department of Physics Eng., Faculty of Sciences, Istanbul Medeniyet University, Istanbul, Turkey
}

\begin{abstract}
In this work, we prepared an ideal $\mathrm{Cu} / \mathrm{DNA} / \mathrm{n}$-InP biopolymer-inorganic Schottky sandwich device formed by coating a nInP semiconductor wafer with a biopolymer DNA. The $\mathrm{Cu} / \mathrm{DNA} / \mathrm{n}-\mathrm{InP}$ contact showed a good rectifying behavior. The ideality factor value of 1.08 and the barrier height $\left(\Phi_{\mathrm{b}}\right)$ value of $0.70 \mathrm{eV}$ for the $\mathrm{Cu} / \mathrm{DNA} / \mathrm{n}-\mathrm{InP}$ device were determined from the forward bias I-V characteristics. It was seen that the $\Phi_{\mathrm{b}}$ value of $0.70 \mathrm{eV}$ obtained for the $\mathrm{Cu} / \mathrm{DNA} / \mathrm{n}$-InP contact was significantly larger than the value of $0.48 \mathrm{eV}$ of conventional $\mathrm{Cu} / \mathrm{n}$-InP Schottky diodes. Modification of the interfacial potential barrier of $\mathrm{Cu} / \mathrm{n}-\mathrm{InP}$ diode was achieved using a thin interlayer of DNA biopolymer. This was attributed to the fact that DNA biopolymer interlayer increased the effective barrier height by influencing the space charge region of InP.
\end{abstract}

Keywords: Schottky diodes; interfaces; semiconductors; electrical properties

(C) Wroclaw University of Technology.

\section{Introduction}

Organic materials have intensively been investigated due to their wide range of applications in electronics technology. For example, many devices using polymeric [1-7] and nonpolymeric organic materials [8-15], including light emitting diodes and devices, such as an inorganic/organic and a metal/organic heterostructures, have been fabricated. Attractive features of these materials offer the possibility for device processing, compatibility with flexible substrates, and low materials consumption for ultra thin molecular films, all of which give the prospect of cheaper photovoltaic energy generation [16]. Large-scale production is easier than in case of inorganic materials. The greatest feature of organic materials is that they can be tuned chemically, in order to adjust separately the band gap, valence and conduction band energies, charge transport as well as the solubility or other structural properties [16]. Owing to their stability and barrier height $(\mathrm{BH})$ enhancement properties, nonpolymeric organic compounds have been

*E-mail: omergullu@gmail.com employed particularly in electronic devices [11, 17-19]. Forrest et al. [17, 20] and Antohe et al. [21] obtained metal-insulator-semiconductor (MIS) contacts by sublimation of nonpolymeric organic thin films on a semiconductor substrate and subsequent evaporation of different metals. Afterwards, they measured the ideality factor and the BH. Aydin et al. [19] obtained MIS contacts by deposition of a $\beta$-carotene solution on the top of Si substrate, and after evaporation of the solution, measured the ideality factor and the BH. Kilicoglu et al. [11] obtained MIS contacts by deposition of a methyl red solution on the top of $\mathrm{Si}$ substrate, and measured the ideality factor and the $\mathrm{BH}$. They showed that these contacts for nonpolymeric thin films, formed at metal/semiconductor interface, had rectification properties and enhanced the $\mathrm{BH}$ [22].

InP is one of the most promising semiconducting materials for microwave and optoelectronic devices. However, low barrier height and high leakage current of InP Schottky diodes, owing to surface Fermi level pinning, have made it difficult to realise InP-based devices. One method for enhancing the effective Schottky barrier height is to form 
a tunnel MIS structure [23]. Another method is to release the surface Fermi level pinning and use a high work function metal [24]. Assuming that the surface Fermi level pinning is caused by high surface state density, passivation technology is needed to reduce the surface states of InP. To fabricate MIS Schottky diodes with an enhanced barrier height, it is useful to develop an in situ process in which surface passivation and insulating film deposition are carried out successively [25].

It is believed that DNA could be a good material to fabricate organic semiconductor devices, such as solar cells and MIS diodes [26]. So the need to develop even smaller electronic devices may eventually lead us to the domain of DNA electronics. In fact, DNA offers a solution to many of the hurdles that need to be overcome. It is the best nanowire ever obtained, and it is able to self-assemble, self-replicate and adopt various states and conformations. The most important property of DNA for a biomolecular engineer is its ability to self-assemble, which makes it possible to produce nanostructures with a precision that is not achievable with classical silicon-based technologies. Furthermore, it is cheap, as the cost of DNA is just a few US cents [27]. Recently, there have been attempts in the literature to experimentally and theoretically demonstrate the conducting behaviors of DNA molecules and direct electrical conductivity measurements were used in these studies [28-33]. Still, there is a lack of knowledge and debates about the exact charge transport mechanism [28, 34]. As has been recently shown in the relevant literature [29, 30, 34-36], DNA molecules could function as nano-sized semiconductor materials or non-semiconductor materials, or as insulator or metal [37]. The most recent [38] argues that DNA is an insulator, or at least a wide band gap semiconductor and exhibits nonlinear I-V (current-voltage) characteristics [39]. In this study, we have fabricated a DNA-based organic-on-inorganic (OI) Schottky device by solution processing method. By considering the electrical properties of the device we have evaluated the effects of DNA insulator interlayer on a conventional metal/semiconductor.
Our aim was to study the suitability of organic-on-inorganic semiconductor contact barrier diodes and possibility for their use in barrier modification of InP metal-semiconductor (MS) diodes.

\section{Experimental}

\subsection{Chemical cleaning and ohmic contact formation}

In this study, an organic/inorganic semiconductor device was prepared using one-side polished (as received from the manufacturer) n-type InP wafer. The wafer was chemically cleaned with $3 \mathrm{H}_{2} \mathrm{SO}_{4}+\mathrm{H}_{2} \mathrm{O}_{2}+\mathrm{H}_{2} \mathrm{O}$ (20 s boiling). The native oxide on the front surface of $n$-InP was removed in a $\mathrm{HF}: \mathrm{H}_{2} \mathrm{O}(1: 10)$ solution and finally the wafer was rinsed in deionized (DI) water for $30 \mathrm{~s}$. Before forming DNA layer on n-InP substrate, the ohmic contact was made by evaporating indium metal on the back of the substrate, followed by a temperature treatment at $350{ }^{\circ} \mathrm{C}$ for $60 \mathrm{~s}$ in $\mathrm{N}_{2}$ atmosphere.

\subsection{Deposition of DNA film and top con- tact metallization}

After the cleaning procedures and ohmic contact metallization, the DNA film was directly formed by adding $10 \mu \mathrm{L}$ of DNA solution in water on the front surface of the n-InP wafer, and dried naturally by evaporating the solvent in $\mathrm{N}_{2}$ atmosphere for one day. Here, we selected an amount of $10 \mu \mathrm{L}$ of the DNA solution by considering and testing various factors that could affect a given DNA film thickness and homogeneity, depending on the solution concentration and substrate area. The quality of organic thin films should be also related to other factors, such as the film-forming ability, the molecular symmetry and structure [40]. The contacting top metal dots with a diameter of $1.0 \mathrm{~mm}$ were formed by evaporation of $\mathrm{Cu}$. We also fabricated $\mathrm{Cu} / \mathrm{n}-\mathrm{InP}$ reference diode without the organic layer to compare its parameters with the electrical parameters of the $\mathrm{Cu} / \mathrm{DNA} / \mathrm{n}-\mathrm{InP}$ (MIS) device. All evaporation processes were carried out in a vacuum coating unit at about $10^{-3} \mathrm{~Pa}$. 


\subsection{Electrical measurements}

Current-voltage (I-V) measurement was carried out using a Keithley 487 picoammeter/voltage source at room temperature and in dark conditions (Fig. 1).

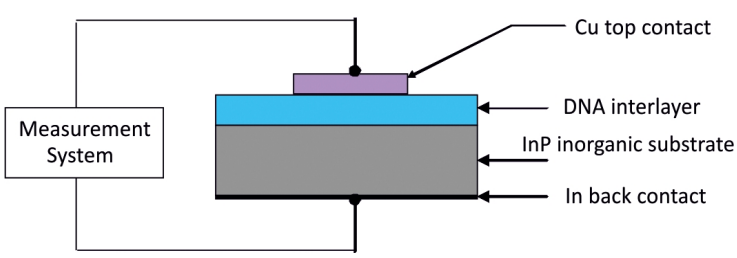

Fig. 1. The scheme for electrical characterization of the $\mathrm{Cu} / \mathrm{DNA} / \mathrm{n}$-InP MIS diode.

\section{Results and discussion}

\subsection{Electrical properties of the Cu/DNA/n-InP structure}

According to the thermionic emission (TE) theory, the forward bias I-V characteristics of Schottky contacts for $\mathrm{qV} \gg 3 \mathrm{kT}$ can be expressed as [41, 42]:

$$
I=I_{0} \exp \left(\frac{q V}{n k T}\right)
$$

where $\mathrm{V}$ is the voltage drop across the Schottky barrier, $\mathrm{n}$ is the ideality factor and $\mathrm{I}_{0}$ is the saturation current determined by:

$$
I_{0}=A A^{*} T^{2} \exp \left(\frac{-q \Phi_{b}}{k T}\right)
$$

where $\mathrm{A}$ is the diode area, $\mathrm{A}^{*}$ is the effective Richardson constant, $\mathrm{k}$ is Boltzmann constant, $\mathrm{T}$ is the temperature, $\Phi_{\mathrm{b}}$ is the barrier height and $\mathrm{q}$ is the electron charge. $\mathrm{n}$ is a measure of conformity of the diode to pure thermionic emission and it is determined from the slope of the straight line region of the forward bias $\ln \mathrm{I}-\mathrm{V}$ characteristics through the relation:

$$
n=\frac{q}{k T} \frac{d V}{d(\ln I)}
$$

In the usual analysis of experimental data on Schottky contacts, the barrier height is determined from the current axis intercept of the linear regions of the forward bias I-V plots. However, this is an apparent barrier height $\Phi_{b}$ when an interfacial layer is present. The effective or apparent barrier height $\Phi_{\mathrm{b}}$ is given by:

$$
\Phi_{b}=\frac{k T}{q} \ln \left(\frac{A^{*} A T^{2}}{I_{0}}\right)
$$

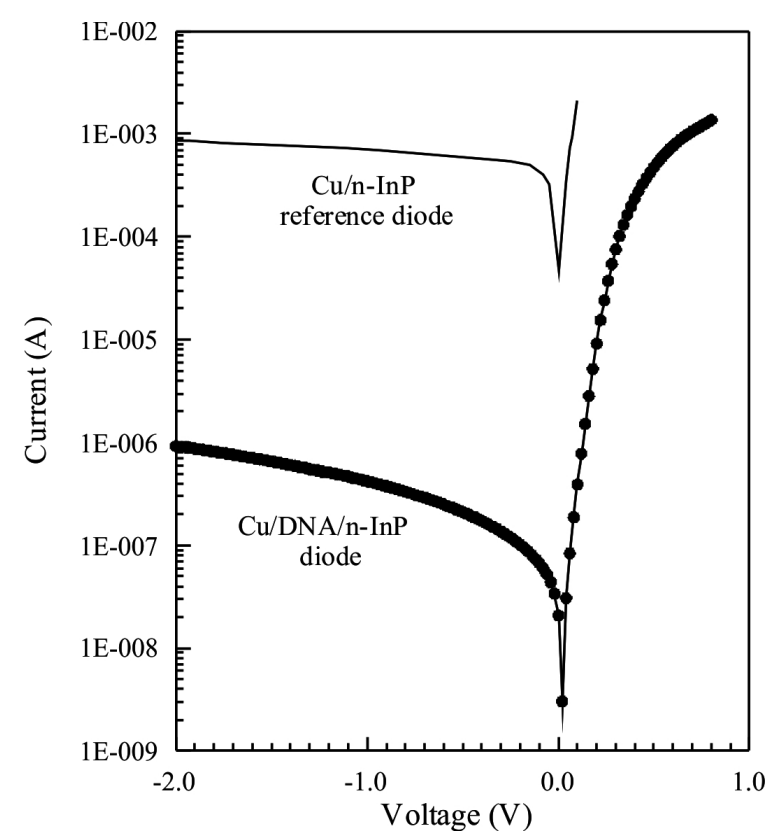

Fig. 2. Current-voltage characteristics of the $\mathrm{Cu} / \mathrm{DNA} / \mathrm{n}$-InP MIS diode and $\mathrm{Cu} / \mathrm{n}$-InP reference diode.

Fig. 2 shows the experimental semi-log I-V characteristics of the reference $(\mathrm{Cu} / \mathrm{n}-\mathrm{InP})$ and the $\mathrm{Cu} / \mathrm{DNA} / \mathrm{n}$-InP Schottky device at room temperature. As clearly seen from Fig. 2, the Cu/DNA/nInP Schottky structure shows a good rectifying property. The weak voltage dependence of the reverse-bias current and the exponential increase of the forward-bias current are characteristic properties of rectifying interfaces. The current curve in forward bias quickly becomes dominated by a series resistance from contact wires or bulk resistance of the organic semiconductor and inorganic semiconductor, giving rise to the curvature at high current in the semi-log I-V plot. The figure indicates that the reverse current is reduced by more than two orders of magnitude compared with the case 
of Schottky junction without DNA interlayer. By thermionic emission (TE) theory [41, 42], the ideality factor $\mathrm{n}$ and $\mathrm{BH}\left(\Phi_{\mathrm{b}}\right)$ can be obtained from the slope and the current axis intercept of the linear regions of the forward bias I-V plots, respectively.

The values of the $\mathrm{BH}$ and the ideality factor for the $\mathrm{Cu} / \mathrm{DNA} / \mathrm{n}$-InP diode have been calculated as $0.70 \mathrm{eV}$ and 1.08 , respectively. The ideality factor determined by the image-force effect alone should be close to 1.01 or 1.02 [43-45]. Our data clearly indicate that the diode has the ideality factor which agrees well with this value. Higher values of ideality factors are attributed to secondary mechanisms which include interface dipoles due to interface doping or specific interface structure as well as fabrication-induced defects at the interface [4346]. According to Tung et al. [45], the high values of $n$ can also be attributed to the presence of a wide distribution of low-SBH patches caused by lateral barrier inhomogeneity. Also, the image-force effect, recombination-generation, and tunneling may be possible mechanisms that could lead to an ideality factor value greater than unity [41].

$\Phi_{\mathrm{b}}$ value of $0.70 \mathrm{eV}$ that we have obtained for the $\mathrm{Cu} / \mathrm{DNA} / \mathrm{n}$-InP MIS device due to DNA biopolymer layer is remarkably higher than those achieved with conventional metal/semiconductor contacts, such as $\mathrm{Cu} / \mathrm{n}$-InP reference diode, where $\Phi_{\mathrm{b}}$ is $0.46 \mathrm{eV}$. This may be ascribed to DNA interlayer modifying the effective barrier height by influencing the space charge region of the inorganic InP substrate [14]. Thereby, it is known that the DNA film forms a physical barrier between the metal and InP inorganic substrate, preventing the metal from directly contacting the InP surface. The DNA organic interlayer appears to cause a significant modification of interface states even though the organic-inorganic interface becomes abrupt and unreactive [14, 47]. Thus, the change in barrier height can qualitatively be explained by an interface dipole induced by the organic layer passivation [12, 15]. Kampen et al. [12] have observed by photoemission spectroscopy investigations that the sulphur passivation reduces the surface band bending on n-type doped GaAs, whereas the band bending on the surfaces of p-type doped GaAs increases. Zahn et al. [13, 48] showed that in ultraviolet photoemission spectroscopy (UPS), electron affinities of substrates can be systematically varied with a known band gap to create an energy offset between the conduction band minimum of n-doped inorganic semiconductors and the lowest unoccupied molecular orbital (LUMO) of organic molecular films at the interfaces. Furthermore, van Meirhaeghe et al. [49] reported that passivation by hydrogen directly reduced the barrier height on nGaAs and increased p-type one.

It is well known that the downward concave curvature of the forward bias current-voltage plots at sufficiently large voltages is caused by the effect of series resistance $\left(R_{s}\right)$, apart from the interface states, which are in equilibrium with the semiconductor [50]. The $R_{S}$ values have been calculated using a method developed by Cheung and Cheung [51], which has been used in practice in $[52,53]$. According to Cheung and Cheung, the forward bias I-V characteristics taking into account the TE of a Schottky diode with the series resistance can be expressed as:

$$
I=I_{0} \exp \left[\frac{q\left(V-I R_{S}\right)}{n k T}\right]
$$

where $\mathrm{IR}_{\mathrm{S}}$ term is the voltage drop across the series resistance of the device. The values of the series resistance can be determined from following expressions using equation 5 :

$$
\begin{gathered}
\frac{d V}{d(\ln I)}=\frac{n k T}{q}+I R_{s} \\
H(I)=V-\left(\frac{n k T}{q}\right) \ln \left(\frac{I}{A A^{*} T^{2}}\right)
\end{gathered}
$$

where $\mathrm{H}(\mathrm{I})$ is given as follows:

$$
H(I)=n \Phi_{b}+I R_{S}
$$

A plot of $\frac{d V}{d(\ln I)}$ vs. $I$ is linear and gives $R_{s}$ as the slope and $\frac{n k T}{q}$ as the $y$-axis intercept from equation 6. Fig. 3 shows a plot of $\frac{\mathrm{dV}}{\mathrm{d}(\ln I)}$ vs. I at room temperature. The values of $n$ and $R_{S}$ have been calculated as $n=1.52$ and $R_{S}=299.0 \Omega$, respectively. 
It is observed that there is a higher difference between the value of $n$ obtained from the forward-bias ln I-V plot and that obtained from the $\mathrm{dV} / \mathrm{d}(\operatorname{lnI})$ I curve. This can be attributed to the existence of a series resistance and interface states and to the voltage drop across the insulator interfacial layer (native oxide plus DNA biopolymer layer) [51]. Another explanation for the high series resistance of $\mathrm{Cu} / \mathrm{DNA} / \mathrm{n}-\mathrm{InP}$ MIS diode involves the influence of the bias voltage drop across the DNA insulator layer [53]. Besides, H(I) vs. I plot has to be linear according to Turut et al. [51]. The slope of this plot gives a different value of $R_{S}$. Using the value of the $\mathrm{n}$ obtained from equation 6 , the value of $\Phi_{\mathrm{b}}$ is obtained from the $\mathrm{y}$-axis intercept. $\mathrm{H}(\mathrm{I})$ vs. I curve is shown in Fig. 3. From $\mathrm{H}(\mathrm{I})$ vs. I plot, $\Phi_{\mathrm{b}}$ and $\mathrm{R}_{\mathrm{S}}$ have been calculated as $0.66 \mathrm{eV}$ and $300.0 \Omega$, respectively.

Norde proposed an alternative method to determine the value of series resistance. The following function has been defined in the modified Norde's method [54]:

$$
F(V)=\frac{V}{\gamma}-\frac{1}{\beta} \ln \left(\frac{I(V)}{A A^{*} T^{2}}\right)
$$

where $\gamma$ is an integer (dimensionless) greater than $\mathrm{n}, \mathrm{I}(\mathrm{V})$ is a current obtained from the I-V curve and $\beta$ is a temperature-dependent value calculated with $\beta=\mathrm{q} / \mathrm{kT}$. Once the minimum of the F vs. V plot is determined, the value of barrier height can be obtained from equation 10 , where $F\left(V_{0}\right)$ is the minimum point of $F(V)$ and $V_{0}$ is the corresponding voltage:

$$
\Phi_{b}=F\left(V_{0}\right)+\frac{V_{0}}{\gamma}-\frac{k T}{q}
$$

Fig. 4 shows the $\mathrm{F}(\mathrm{V})-\mathrm{V}$ plot of the junction. From Norde's functions, $\mathrm{R}_{\mathrm{s}}$ value can be determined as:

$$
R_{s}=\frac{k T(\gamma-n)}{q I}
$$

From the F-V plot, using $\mathrm{F}\left(\mathrm{V}_{0}\right)=0.62 \mathrm{~V}$ and $\mathrm{V}_{0}=0.26 \mathrm{~V}$ values, the values of $\Phi_{\mathrm{b}}$ and $\mathrm{R}_{\mathrm{s}}$ of the $\mathrm{Cu} / \mathrm{DNA} / \mathrm{n}$-InP structure have been determined as $0.73 \mathrm{eV}$ and $640.0 \Omega$, respectively. There

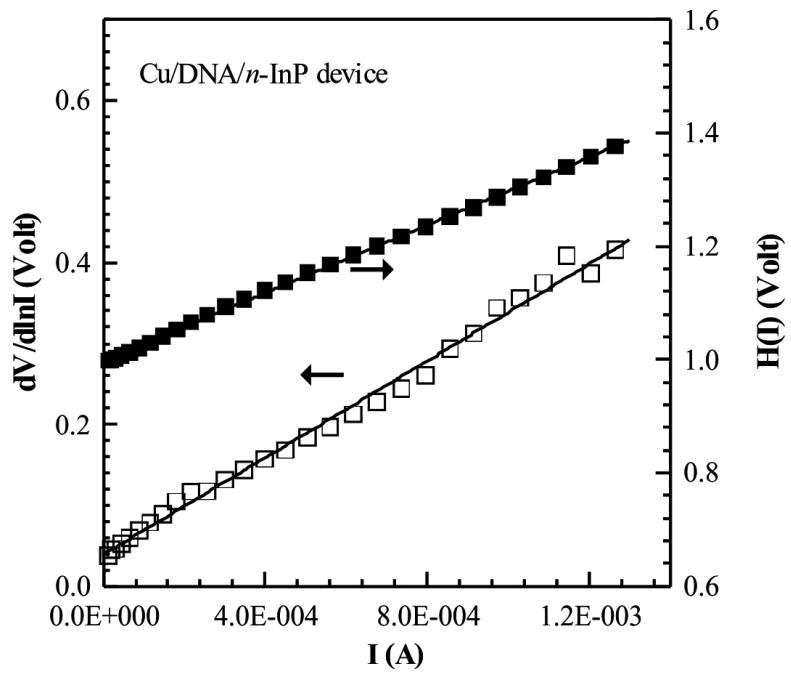

Fig. 3. dV/dlnI-I and H(I)-I plots obtained from the experimental I-V data in Fig. 2.

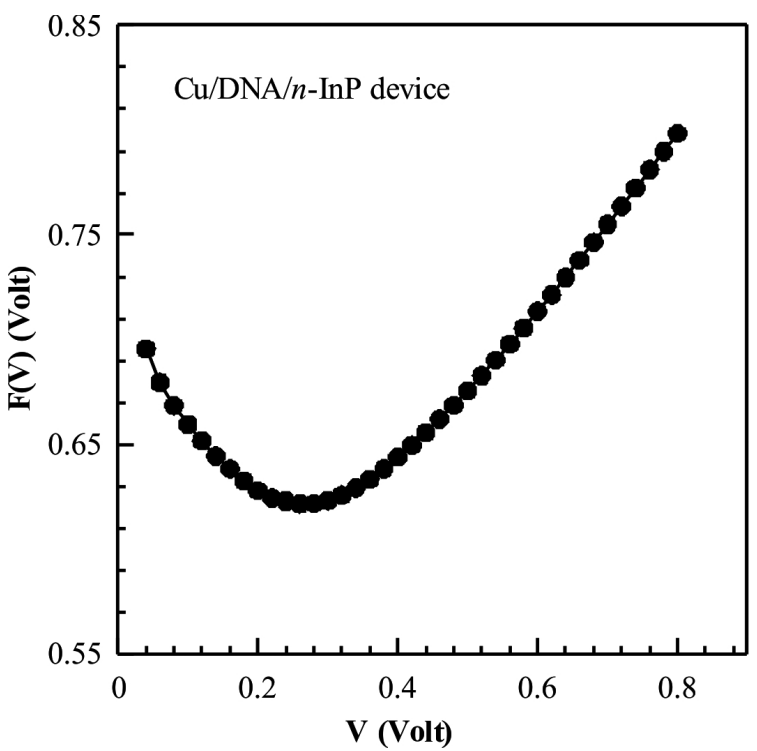

Fig. 4. F(V)-V plots obtained from the experimental I$\mathrm{V}$ data in Fig. 2.

are small differences in the values of $\Phi_{\mathrm{b}}$ obtained from the forward bias $\ln \mathrm{I}-\mathrm{V}$, Cheung functions and Norde functions. The small differences in the barrier height values for the device, obtained by these three methods may be attributed to the extraction of the forward bias current-voltage plot from different regions [55]. However, the value of the series resistance obtained from Norde functions is higher than that obtained from Cheung functions. Cheung 
functions are only applied to the nonlinear region existing at high voltages of the forward bias ln IV characteristics, while Norde's functions are applied to the full forward bias region of the $\ln \mathrm{I}-\mathrm{V}$ characteristics of the junctions [55]. The value of series resistance may also be high for the higher ideality factor values. After all, the value of series resistance is very high for this device. This indicates that the series resistance is a currentlimiting factor for this structure. The effect of series resistance is usually modeled with a series combination of a diode and a resistance $R_{s}$. The voltage drop across a diode is expressed in terms of the total voltage drop across the diode and the resistance $R_{s}$. The very high series resistance behavior may be ascribed to the decrease in the exponentially increasing rate of current due to space-charge injection into the DNA thin film at higher forward bias voltage [55]. Furthermore, Norde's model may not be a suitable method, especially for rectifying junctions with a high ideality factor, which is not consistent with pure thermionic emission theory. Therefore, the series resistance value from Norde functions can be much higher than that one from Cheung model for especially non-ideal rectifying structures $[55,56]$.

\subsection{Interfacial properties of the $\mathrm{Cu} / \mathrm{DNA} / \mathrm{n}-\mathrm{InP}$ MIS structure}

For a metal/semiconductor diode having interface states in equilibrium with the semiconductor, the ideality factor $\mathrm{n}$ becomes greater than unity as proposed by Card and Rhoderick [57] and then interface state density $\mathrm{N}_{\mathrm{ss}}$ is given by:

$$
N_{S S}=\frac{1}{q}\left[\frac{\varepsilon_{i}}{\delta}(n(V)-1)-\frac{\varepsilon_{s}}{w}\right]
$$

where $\mathrm{w}$ is the space charge width, $\varepsilon_{\mathrm{s}}$ is the permittivity of the semiconductor, $\varepsilon_{\mathrm{i}}$ is the permittivity of the interfacial layer, $\delta$ is the thickness of organic layer, and $\mathrm{n}(\mathrm{V})=\frac{\mathrm{V}}{(\mathrm{kT} / \mathrm{q}) \ln \left(\mathrm{I} / \mathrm{I}_{0}\right)}$ is a voltagedependent ideality factor. In n-type semiconductors, the energy of the interface states $\mathrm{E}_{\mathrm{ss}}$ with respect to the bottom of the conduction band at the surface of the semiconductor is given by:

$$
E_{c}-E_{s s}=q \Phi_{b}-q V
$$

where $\mathrm{V}$ is the voltage drop across the depletion layer and $\Phi_{b}$ is the effective barrier height. The energy distribution or density distribution curves of the interface states can be determined from experimental data of this region of forward bias I-V plot. Substituting the voltage dependent values of $\mathrm{n}$ and the other parameters in equation 12 , the $\mathrm{N}_{\mathrm{ss}}$ vs. $\mathrm{E}_{\mathrm{c}}-\mathrm{E}_{\mathrm{ss}}$ plot was obtained as shown in Fig. 5. It is seen that for the structure the interface state density $\mathrm{N}_{\mathrm{ss}}$ has an exponential rise with bias from the midgap towards the top of the conduction band. In this structure the deposition of DNA on the inorganic semiconductor can generate a large number of interface states at the semiconductor surface that strongly influence the properties of the device. When this structure is considered as a Schottky diode, the diode comprises a high-resistivity layer (depletion layer) in series with a low-resistivity layer, which has its own capacitance and resistance. The chemical interaction at the interface of DNA and the $n$-InP, may give rise to new interface states similar to the other oxide-organic interface states.

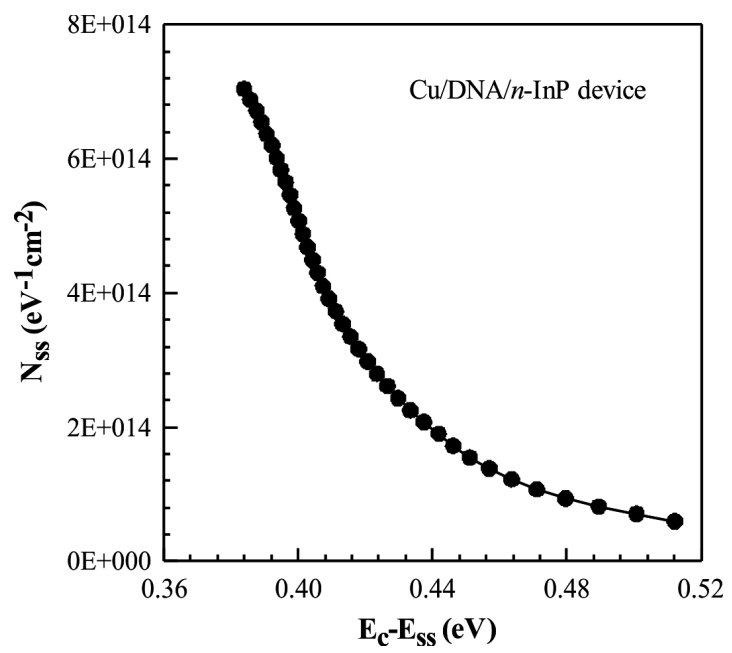

Fig. 5. $\mathrm{N}_{\mathrm{ss}}-\left(\mathrm{E}_{\mathrm{c}}-\mathrm{E}_{\mathrm{ss}}\right)$ plot of the $\mathrm{Cu} / \mathrm{DNA} / \mathrm{n}-\mathrm{InP}$ MIS device.

\section{Conclusion}

In conclusion, we have studied the electrical characteristics of $\mathrm{Cu} / \mathrm{DNA} / \mathrm{n}$-InP MIS Schottky structures formed by evaporation of an organic material solution directly from a $\mathrm{n}$-InP substrate. It 
has been observed that the DNA thin film on the n-InP substrate has shown a good rectifying behavior. The barrier height and ideality factor of the device have been calculated from the I-V characteristics. We have studied the suitability of organic-oninorganic semiconductor diodes for the use in barrier modification of InP MS diodes. In addition, we have compared the parameters of the $\mathrm{Cu} / \mathrm{DNA} / \mathrm{n}$ InP MIS Schottky diodes with those of conventional MS diodes. We have observed that the $\Phi_{\mathrm{b}}$ value of $0.70 \mathrm{eV}$ obtained for the $\mathrm{Cu} / \mathrm{DNA} / \mathrm{n}-\mathrm{InP}$ MIS device is significantly larger than the $\mathrm{BH}$ value of a conventional $\mathrm{Cu} / \mathrm{n}$-InP MS contact. Thus, the modification of the interfacial potential barrier for metal/InP diodes has been achieved using the DNA biopolymer interlayer. This has been attributed to the fact that the DNA interlayer increases the effective $\Phi_{\mathrm{b}}$ by influencing the space charge region of InP.

\section{Acknowledgements}

The authors wish to thank Dr. M. Cankaya and Dr. O. Baris from Atatürk University for DNA supply.

\section{References}

[1] Koezuka H., Eтoh S., J. Appl. Phys., 54 (5) (1983), 2511.

[2] Kurata T., Koezuka H., Tsunoda S., Ando T., J. Phys. D Appl. Phys., 19 (4) (1986), L57.

[3] Turut A., Koleli F., J. Appl. Phys., 72 (2) (1992), 818.

[4] Onganer Y., Saglam M., Turut A., Efeoglu H., TuZEMEn S., Solid State Electron., 39 (1996), 677.

[5] Gupta R., Misra S.C.K., Malhotra B.D., BeLadakere N.N., Chandra S., Appl. Phys. Lett., 58 (1991), 51

[6] Aydogan S., Saglam M., Turut A., J. Phys.Condens. Mat., 18 (9) (2006), 2665.

[7] Camaioni N., Casalbore-Miceli G., Beggiato G., Cristani M., Summonte C., Thin Solid Films, 366 (2000), 211.

[8] Forrest S.R., Schmidt P.H., J. Appl. Phys., 59 (1986), 513.

[9] Gullu O., Pakma O., Turut A., J. Appl. Phys., 111 (2012), 044503.

[10] Samuel M., Menon C.S., Unnikrishnan N.V., Mater. Sci.-Poland, 25 (1) (2007), 177.

[11] Kilicoglu T., Aydin M.E., OcaK Y.S., Physica B, $388(1,2)$ (2007), 244.

[12] Kampen T., Schuller A., Zahn D.R. T., Biel B., Ortega J., Perez R., Flores F., Appl. Surf. Sci., 234 (2004), 341.
[13] Zahn D.R.T., Kampen T.U., Mendez H., Appl. Surf. Sci., 212 - 213 (2003), 423.

[14] Roberts A.R.V., Evans D.A., Appl. Phys. Lett., 86 (2005), 072105.

[15] Bolognesi A., Carlo A.D., Lugli P., Kampen T., Zahn D.R.T., J. Phys.: Condens. Mat., 15 (2003), S2719.

[16] Rajesh K.R., Menon C.S., J. Non-Cryst. Solids, 353 (4) (2007), 398.

[17] Forrest S.R., KAPlan M.L., SchmidT P.H., Feldmann W.L., Yanowski E., Appl. Phys. Lett., 41 (1982), 90.

[18] Cakar M., Temirci C., Turut A., Chemphyschem, 8 (2002), 701.

[19] Aydin M.E., Kilicoglu T., Akkilic K., HosGOREN H., Physica B, 381 (2006), 113.

[20] Forrest S.R., Kaplan M.L., Schmidt P.H., J. Appl. Phys., 55 (1984), 1492.

[21] Antohe S., Tomozeiu N., Gogonea S., Phys. Status Solidi A, 125 (1991), 397.

[22] Ebeoglu M.A., Kilicoglu T., Aydin M.E., Physica B, 395 (2007), 93.

[23] Hattori K., ToriI Y., Solid State Electron., 34 (1991), 527.

[24] Sugiuo T., Sakamoto Y., Sumiguchi T., Nomoto K., Shirafuji J., Jpn. J. Appl. Phys., 32 (1993), L1196.

[25] Sakamoto Y., Sugino T., MiYazaki T., Shirafuji J., Electron. Lett., 31 (1995), 1104.

[26] Gullu O., Turut A., Sol. Energ. Mat. Sol. C., 92 (10) (2008), 1295.

[27] Bhalla V., Bajpai R. P., Bharadwaj L.M., EMBO Rep., 4 (5) (2003), 442.

[28] Hwang J.S., Hwang S.W., Ahn D., Superlattice. Microst., 4 (2003), 433.

[29] Porath D., Bezryadin A., VRies de S., DekKer C., Nature, 403 (2000), 635.

[30] Kasumov A.Y., Kociak M., Gueron S., Reulet B., Volkov V.T., Klinov D.V., Bouchiat H., Science, 291 (2001), 280.

[31] Yoo K.H., Ha D.H., Lee J.O., Park J.W., Kim J., Kim J.J., LeE H.Y., Kawai T., Choi H.Y., Phys. Rev. Lett., 87 (2001), 198102.

[32] Hwang J.S., Kong K.J., Ahn D., Lee G.S., Ahn D.J., HWANG S.W., Appl. Phys. Lett., 81 (2002), 1134.

[33] Li X.Q., YAn Y., J., Appl. Phys. Lett., 79 (2001), 2190.

[34] Storm A.J., VAn Noort J., VRIES DE S., DeKKer C., Appl. Phys. Lett., 79 (2001), 3881.

[35] Cai L., Tabata H., Kawai T., Appl. Phys. Lett., 77 (2000), 3105.

[36] Fink H.W., Schonenberger C., Nature, 398 (1999), 407.

[37] Jo Y.S., LeE Y., RoH Y., Mater. Sci. Eng. C, 23 (2003), 841.

[38] Endres R.G., Cox D.L., Singh R.R.P., Rev. Mod. Phys., 76 (2004), 195.

[39] KWOK H.L., IET Nanobiotechnol., 151 (6) (2004), 193. 
[40] QIU Y., QIAO J., Thin Solid Films, 372 (2000), 265.

[41] RHOdERICK E.H., Williams R.H., MetalSemiconductor Contacts, Clarendon, Oxford, 1988.

[42] SzE S.M., Physics of Semiconductor Devices, Wiley, New York, 1981.

[43] SChMitsdorf R.F., KAMPEN T.U., MONCH W., J. Vac. Sci. Technol. B, 15 (4) (1997), 1221.

[44] Monch W., J. Vac. Sci. Technol. B, 17 (4) (1999), 1867.

[45] Tung R.T., Phys. Rev. B, 45 (23) (1992), 13509.

[46] Vanalme G.M., Goubert L., Meirhaeghe van R.L., Cardon F., Daele Van P., Semicond. Sci. Tech., 14 (1999), 871.

[47] Cakar M., Temirci C., Turut A., Synthetic Met., 142 (2004), 177.

[48] Zahn D.R.T., Park S., Kampen T.U., Vacuum, 67 (2002), 101.

[49] Meirhaeghe VAn R.L., Laflere W.H., Cardon F., J. Appl. Phys., 76 (1) (1994), 403.
[50] Aydogan S., Saglam M., Turut A., Microelectron. Eng., 85 (2008), 278.

[51] Cheung S.K., Cheung N.W., Appl. Phys. Lett., 49 (1986), 85.

[52] Turut A., Saglam M., Efeoglu H., Yalcin N., Yildirim M., Abay B., Physica B, 205 (1995), 41.

[53] Kilicoglu T., Thin Solid Films, 516 (2008), 967.

[54] Karatas S., Altindal S., Turut A., Cakar M., Physica B, 392 (1 - 2) (2007), 43.

[55] Werner J.H., Guttler H.H., J. Appl. Phys., 69 (1991), 1522.

[56] Gullu O., Aydogan S., Turut A., Microelectron. Eng., 85 (2008), 1647.

[57] Card H.C., Rhoderick E.H., J. Phys. D Appl. Phys., 4 (1971), 1589.

Received 2014-12-27

Accepted 2015-06-01 